\title{
Altruistic Behavior Depending on Opponents' Body Weight: An Experimental Approach
}

\author{
Marie Bernard ${ }^{a}$, $\quad$ Steffi G. Riedel-Heller ${ }^{c} \quad$ Claudia Luck-Sikorskia, b \\ antegrated Research and Treatment Center AdiposityDiseases (IFB), University of Leipzig, \\ Leipzig, Germany; 'bSRH University of Applied Health Sciences, Gera, Germany; \\ cInstitute of Social Medicine, Occupational Health and Public Health (ISAP), University of \\ Leipzig, Leipzig, Germany
}

\section{Keywords}

Decision-making behavior $\cdot$ Dictator game $\cdot$ Altruism $\cdot$ Stigma $\cdot$ Obesity

\begin{abstract}
Background: Obesity is a worldwide public health issue, not only because it is associated with numerous comorbid diseases but also because of its impact on the social level. This study aims to investigate (a) whether altruistic behavior differs between people with obesity and people who are not obese, (b) altruistic behavior toward people who are obese, in particular, women who are obese, and (c) implicit and explicit attitudes toward people with obesity as predictors for divergent altruistic behavior. Methods: An experimental approach called the dictator game was applied. In total, 168 participants of normal weight were asked to divide a monetary reward between themselves and two opponents, one person who was obese and one with normal weight. In addition, participants' implicit and explicit attitudes toward people with obesity as well as other sociodemographic data were assessed. Results: We found that altruistic behavior did not differ between obese and nonobese opponents $(t(166)=-0.57$, $p=0.71)$, nor did we find less altruistic attitudes toward women with obesity $(t(85)=-0.03$, $p=0.39$ ). Linear regression models show less altruistic behavior among people with stronger explicit antifat attitudes $(p=0.015)$. However, although we found that participants held implicit attitudes toward people with obesity, these attitudes did not predict altruistic behavior toward people with obesity. Conclusion: Although numerous studies reported discrimination
\end{abstract}


toward people with obesity in several areas of life, we did not find discrimination in form of less altruistic behavior toward people with obesity. Moreover, although we found implicit antifat attitudes among the participants, these attitudes did not predict altruistic behavior toward people of divergent weight groups. Therefore, future research should investigate more intensively the diverse facets of discrimination toward people with obesity, if and to what extent implicit antifat attitudes have a quantifiable impact on the stigmatization and or discrimination process, and the hypotheses in a more hidden way, since manipulation check revealed that the majority of participants anticipated the underlying idea of the dictator game.

(C) 2019 The Author(s)

Published by S. Karger AG, Basel

\section{Background}

Obesity is a worldwide health issue and is not only associated with various comorbid diseases [1] but also with psychological consequences for those affected. Negative psychological consequences occur when people with obesity are confronted with negative stereotypes such as being lazy or less intelligent. These negative stereotypes can be summed up under the term stigmatization. When a person more strongly evaluates obesity as a selfinflicted condition caused by a lack of self-discipline, then he/she automatically associates more negative characteristics with obesity. These negative associations can either be implicit or explicit, depending on the level of awareness. Implicit attitudes occur automatically without people being fully aware of them, whereas explicit attitudes are conscious and reflect a person's opinions or beliefs about a certain group [2]. According to Link and Phelan [3], labeling and linking people to undesirable associations provides justification for devaluating, rejecting, and excluding them. Thus, stigmatization can lead to discrimination [3]. According to Dovidio et al. [4], discrimination can be understood "as biased behavior, which includes not only actions that directly harm or disadvantage another group, but those that unfairly favor one's own group (creating a relative disadvantage for another group". Discrimination toward people with obesity consistently occurs in several areas of life: job prospects, job earnings, in workplaces [5], and in healthcare settings [6]. Recent studies $[7,8]$ have evaluated such discriminating environments as ubiquitous in modern Western societies and outlined women to be at greater risk for weight discrimination as compared to men.

Tajfel and Turner [9] evaluated divergent altruistic behavior, which can be defined as behavior benefiting another person [10], such as members of in-groups versus members of out-groups as a precursor of discrimination.

Apart from gender, educational attainment, employment status, race, and other similar categories, weight status might be an attribution that divides individuals into in-groups (e.g., same weight status) and out-groups (e.g., different weight status). People might therefore act more altruistically toward individuals of their own group ("in-group favoritism") in comparison to individuals of different groups [11].

Against this background, this study aims to investigate altruistic behavior toward divergent weight groups by applying an experimental game called the "dictator game," which was created by Kahneman et al. [12]. Recent studies that used the dictator game as an experimental stimulus have shown that individuals act more altruistically toward members of their in-group compared to members of out-groups [13-16]. To date, the dictator game has not been used to investigate altruistic behavior toward divergent weight groups. We therefore aim to explore the following hypotheses: 


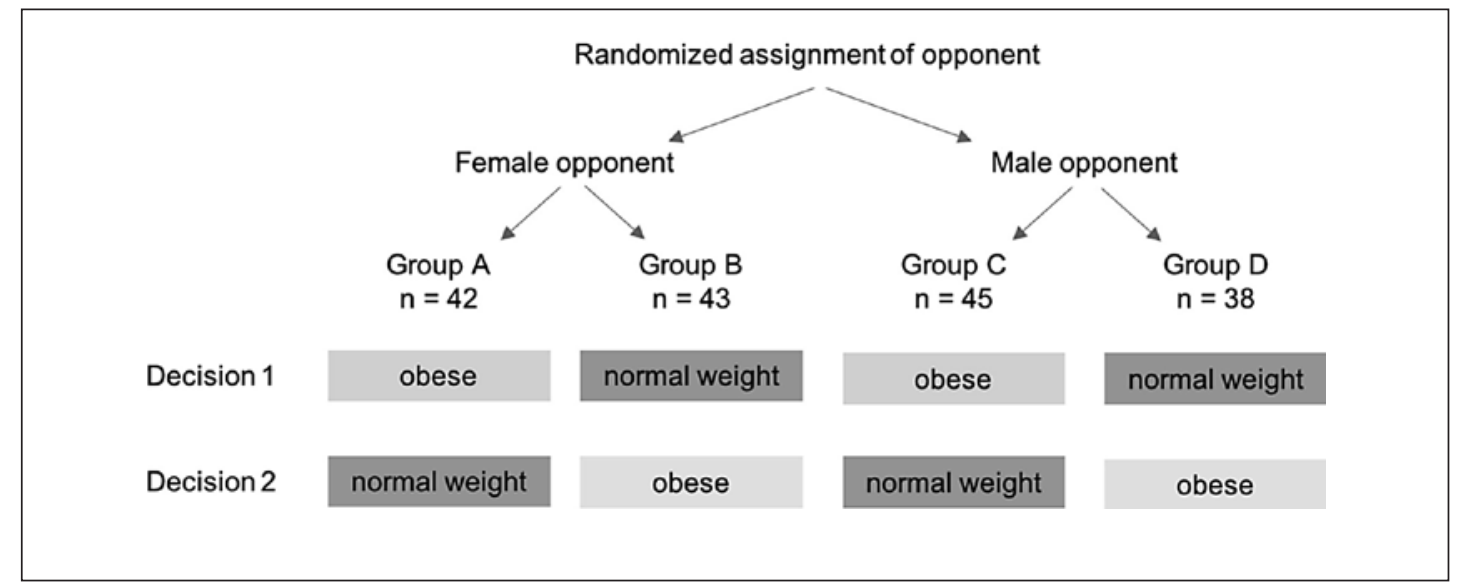

Fig. 1. Randomized assignment of opponents.

\section{Hypothesis 1}

People who are of normal weight are more likely to act less altruistically toward people with obesity.

\section{Hypothesis 2}

Existing literature indicates more negative attitudes toward women with obesity. Therefore, we hypothesize that people will act less altruistically toward women with obesity compared to men with obesity.

\section{Hypothesis 3}

We further hypothesize that when someone holds more negative implicit and/or explicit attitudes toward obesity, then they will act less altruistically toward people with obesity.

\section{Methods}

\section{Sample and Recruitment}

The study was announced in public places and on online platforms, and in this way, participants were recruited. The conditions for participation were determined as follows: men and women between 25 and 45 years of normal weight, defined by a body mass index (BMI) between 18.5 and $<25.0 \mathrm{~kg} / \mathrm{m}^{2}$. In addition, the definition and one example of how to calculate the BMI were given. People who were interested were asked to contact the study team via telephone or email. Upon registration, we invited individuals who met the inclusion criteria to the Institute of Social Medicine, Occupational Health and Public Health (Leipzig University) to take part in the study. This is a pilot study in a convenience sample. While there is evidence that excess weight in a person is indeed linked to negative attitudes [17], studies in this field have always been limited as they did not study behavioral consequences of these negative attitudes by applying an experimental approach. However, when considered a medium effect size $(d=0.5)$, the a priori power analyses for a twosample $t$ test suggested a total sample size of $n=176$ participants with a power of $90 \%$. Despite this calculation, during the predefined period of enrollment, more participants were eligible and therefore tested. Characteristics of the sample are described in the following. 
Fig. 2. Study design and partici-

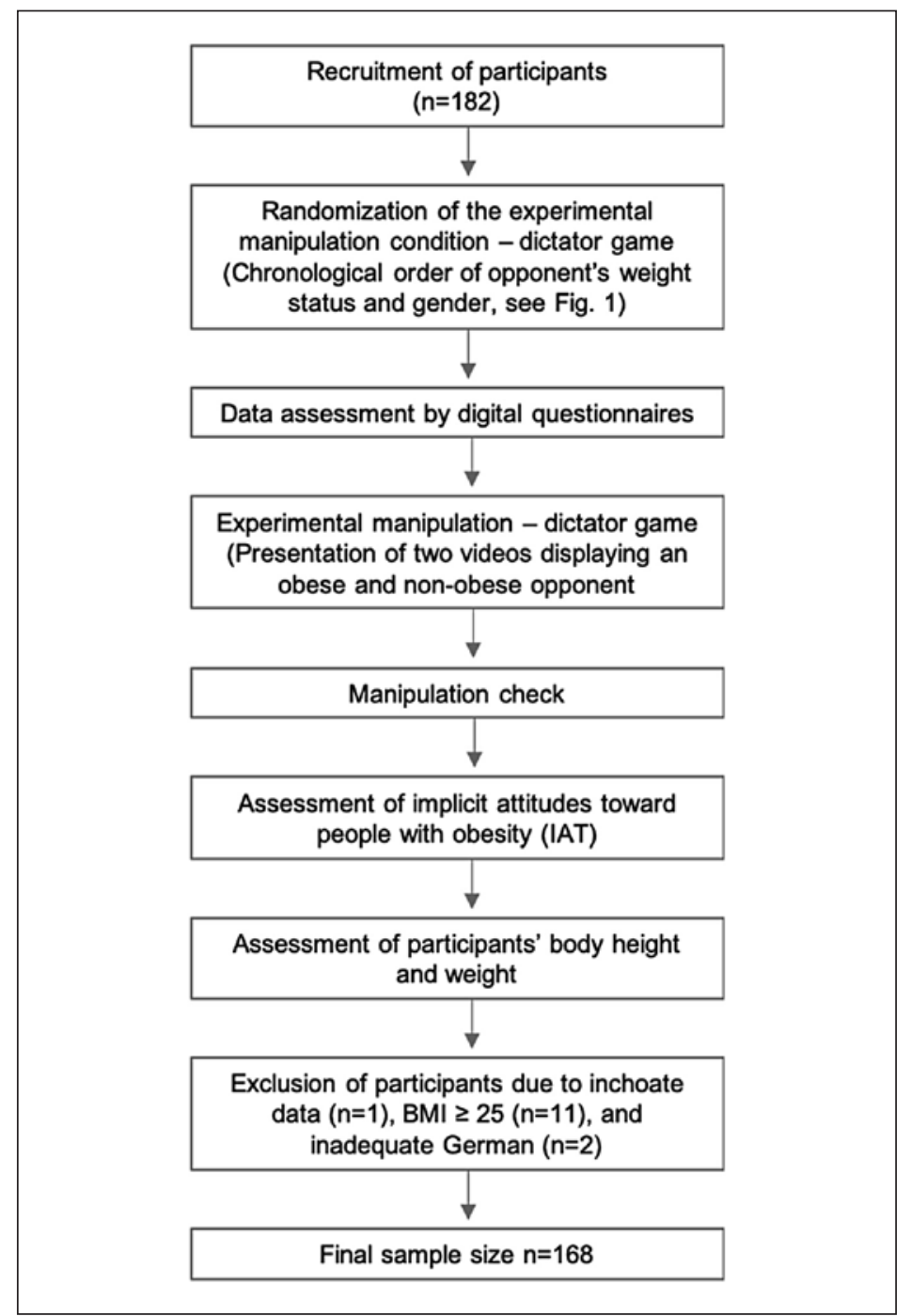
pant flow.

\section{Study Design}

After recruitment, we invited participants for a single appointment. A member of the study team gave a short overview of the procedure and informed participants that their standard payout for participation (EUR 20) could be increased by their decision-making behavior during the study. Participants were then asked to give their written consent. After the member of the study team left the room, participants were asked to complete a digital questionnaire assessing inter alia sociodemographic variables, explicit attitudes toward people with obesity, and their decision-making behavior in general. The latter was merely implemented to distract participants from the true intention of the research question and the dictator game. The dictator game as the experimental manipulation was conducted as follow: two videos were embedded within the digital questionnaire that showed a normal weight and an obese male or female opponent, whereas chronological order was randomized (Fig. 1). Participants were then asked to split an amount of money (EUR 10) between themselves and the opponent presented. After participants completed a manipulation check, they were then asked to complete the Implicit Association Test (IAT) on attitudes toward weight. Finally, the participants' body height and weight were measured by the member of the study team. The order of data assessment and participant flow are provided in Figure 2. 
Bernard et al.: Altruistic Behavior Depending on Opponents' Body Weight

\section{Instruments}

\section{Altruistic Behavior - Experimental Manipulation}

To test whether altruistic behavior depends on the opponent's body weight, an experimental design called the dictator game was applied. The dictator game was originally based on the ultimatum game that was developed to test participants' decision-making behavior in two steps: first, player A is asked to share an amount of money with player B. Second, player $B$ decides whether to accept player A's offer or not. In the case that player B declines the offer, none of the players receive any reward [18]. Player A is therefore forced to share the monetary reward fairly in order to obtain any reward. Although studies showed that two-thirds of players share the reward fairly [18], it remains unclear if player A's decision-making behavior is based on altruism or on their attempt to avoid punishment given by player $B$.

The dictator game created by Kahneman et al. [12] was applied in order to investigate just this type of altruistic behavior. In the dictator game, player A is also asked to share an amount of money with player B. However, within the dictator game player B has no opportunity to accept or decline player A's offer. Therefore, the reward is split between both players according to player A's decision. As mentioned above, two videos were presented to the participants that showed an obese and a nonobese opponent, whereas chronological order and the opponent's gender were randomized. After each video was presented, participants were asked to split an amount of 10 EUR between themselves and the opponent just presented. The participants had to input the amount of money themselves and could include up to two decimals places. The amount of money inputted served as the primary outcome in the statistical analysis.

\section{Attitudes toward People with Obesity}

The Implicit Association Test (IAT) developed by Greenwald et al. [19] was used to measure implicit attitudes toward people with obesity. The IAT measures automatic associations and unconscious prejudices toward specific groups. In this study, we applied the IAT on attitudes toward weight group. The IAT confronts participants with a list of opposing categories (fat and slim, with either good or bad, or with motivated or unmotivated). Participants are then asked to match synonyms for these words under time constraints. The IAT therefore reveals preferences of categorical pairing over another. The underlying idea of the test is that people with stronger implicit attitudes toward obesity perform poorly when they have to combine incongruent adjective pairs ("good" with "fat" and "bad" with "thin"). The IAT scores were calculated by subtracting the number of words correctly classified in the incongruent task from correctly classified words in the congruent tasks (IAT congruent - IAT $_{\text {incongruent }}$ ). Positive differences indicate a more negative implicit attitude toward people with obesity, whereas negative differences display a more positive view. The IAT showed excellent reliability for the congruent task (Cronbach's alpha $=0.95$ ) as well as for the incongruent task (Cronbach's alpha $=0.93$ ).

Explicit attitudes toward people with obesity were assessed by using the Fat Phobia Scale (FPS), which was designed by Bacon et al. [20]. The FPS measures semantic differentials and contains 14 antonymous pairs of adjectives such as "lazy" and "industrious" or "no will power" and "has will power." Participants are asked to classify people with obesity on a 5-point scale ( 1 = positive attitudes; 5 = negative attitudes) between these antonyms. The FPS showed good reliability with a Cronbach's alpha of 0.84 .

\section{Sociodemographic Characteristics}

Within the digital questionnaire, participants were asked to provide information regarding their educational attainment, level of income, age, and other sociodemographic 
Bernard et al.: Altruistic Behavior Depending on Opponents' Body Weight

Table 1. Characteristics of participants: mean values of decision-making behavior within the first played dictator game, implicit (IAT) and explicit (FPS) antifat attitudes compared between female and male participants

\begin{tabular}{|c|c|c|c|c|c|c|}
\hline & \multicolumn{2}{|c|}{ Total $(n=168)$} & \multicolumn{2}{|c|}{ Women $(n=89)$} & \multicolumn{2}{|c|}{$\operatorname{Men}(n=79)$} \\
\hline \multicolumn{7}{|l|}{ Education } \\
\hline Secondary school & 40 & $(22.35)$ & 23 & $(25.00)$ & 17 & $(19.54)$ \\
\hline Technical college & 8 & $(4.76)$ & 3 & $(3.26)$ & 5 & $(5.75)$ \\
\hline Higher school degree & 130 & (72.37) & 66 & $(71.74)$ & 64 & $(73.56)$ \\
\hline Other & 1 & $(0.56)$ & - & - & 1 & $(1.15)$ \\
\hline \multicolumn{7}{|l|}{ Household income } \\
\hline$<500$ EUR & 16 & $(8.94)$ & 9 & $(9.78)$ & 7 & $(8.05)$ \\
\hline $500 \leq 1,000$ EUR & 49 & $(27.37)$ & 21 & $(22.83)$ & 28 & (32.18) \\
\hline $1,000 \leq 1,500$ EUR & 43 & $(24.02)$ & 20 & $(21.74)$ & 23 & $(26.44)$ \\
\hline $1,500 \leq 2,000$ EUR & 24 & (13.41) & 11 & $(11.96)$ & 13 & $(14.94)$ \\
\hline $2,000 \leq 2,500$ EUR & 11 & $(6.15)$ & 6 & $(6.52)$ & 5 & $(5.75)$ \\
\hline $2,500 \leq 3,000$ EUR & 9 & $(5.03)$ & 8 & $(8.70)$ & 1 & $(1.15)$ \\
\hline $3,000 \leq 3,500$ EUR & 8 & $(4.47)$ & 6 & $(6.52)$ & 2 & $(2.30)$ \\
\hline $3,500 \leq 4,000$ EUR & 2 & $(1.12)$ & 1 & $(1.09)$ & 1 & $(1.15)$ \\
\hline $4,000 \leq 4,500$ EUR & 6 & $(3.35)$ & 3 & $(3.26)$ & 3 & $(3.45)$ \\
\hline$>4,500$ EUR & 6 & $(3.35)$ & 4 & $(4.35)$ & 2 & $(2.30)$ \\
\hline "I don't know" & 3 & $(1.68)$ & 2 & $(2.17)$ & 1 & $(1.15)$ \\
\hline "Prefer not to say" & 2 & $(1.12)$ & 1 & $(1.09)$ & 1 & $(1.15)$ \\
\hline \multicolumn{7}{|c|}{ Allocated monetary reward in Euro with first opponent } \\
\hline Obese & \multicolumn{2}{|c|}{$4.41 \pm 0.18$} & \multicolumn{2}{|c|}{$4.51 \pm 0.16$} & \multicolumn{2}{|c|}{$4.30 \pm 0.31$} \\
\hline Female & \multicolumn{2}{|c|}{$4.36 \pm 1.31$} & \multicolumn{2}{|c|}{$4.66 \pm 1.09$} & \multicolumn{2}{|c|}{$4.04 \pm 1.45$} \\
\hline Male & \multicolumn{2}{|c|}{$4.45 \pm 1.90$} & \multicolumn{2}{|c|}{$4.37 \pm 0.92$} & \multicolumn{2}{|c|}{$4.52 \pm 2.48$} \\
\hline Normal weight & \multicolumn{2}{|c|}{$4.25 \pm 0.21$} & \multicolumn{2}{|c|}{$4.12 \pm 0.24$} & \multicolumn{2}{|c|}{$4.43 \pm 0.37$} \\
\hline Female & \multicolumn{2}{|c|}{$4.50 \pm 1.33$} & \multicolumn{2}{|c|}{$4.49 \pm 1.28$} & \multicolumn{2}{|c|}{$4.51 \pm 1.44$} \\
\hline Male & \multicolumn{2}{|c|}{$3.97 \pm 2.35$} & \multicolumn{2}{|c|}{$3.65 \pm 1.97$} & \multicolumn{2}{|c|}{$4.35 \pm 2.75$} \\
\hline Participants' BMI & \multicolumn{2}{|c|}{$21.9 \pm 1.59$} & \multicolumn{2}{|c|}{$21.55 \pm 1.51$} & \multicolumn{2}{|c|}{$22.37 \pm 1.58$} \\
\hline Age & \multicolumn{2}{|c|}{$32.51 \pm 5.80$} & \multicolumn{2}{|c|}{$33.27 \pm 5.72$} & \multicolumn{2}{|c|}{$31.66 \pm 5.81$} \\
\hline FPS (scale 1-5) & \multicolumn{2}{|c|}{$3.55 \pm 0.47$} & $3.54 \pm$ & .46 & $3.56 \pm$ & .48 \\
\hline
\end{tabular}

Values are presented as $n(\%)$ or mean \pm SD. BMI, body mass index; IAT, Implicit Association Test; FPS, Fat Phobia Scale ( 1 = positive attitudes; 5 = negative attitudes).

details. In addition, participants' body weight and height were measured by a member of the study team at the end of the assessment by using an electronic digital scale, accurate to 100 g. A locally manufactured standard measuring board, with increments in millimeters, was used to measure participants' height.

\section{Manipulation Check}

After participants played the two dictator games, a manipulation check was implemented within the digital questionnaire. Participants had to answer the question: "What do you think was the intension of the experiment?"

\section{Statistical Analysis}

All analyses were run with STATA 14.1 [21]. We conducted $t$ tests to analyze group differences and multivariate regression models to find significant predictors for divergent altruistic behavior. We also conducted Bonferroni correction family-wise for multiple testing [22] and did post hoc analyses, such as bivariate analyses between altruistic behavior and explicit as well as implicit antifat attitudes. We analyzed not only intraindividual differences in altru- 
Fig. 3. Mean value of IAT scores (congruent vs. incongruent).

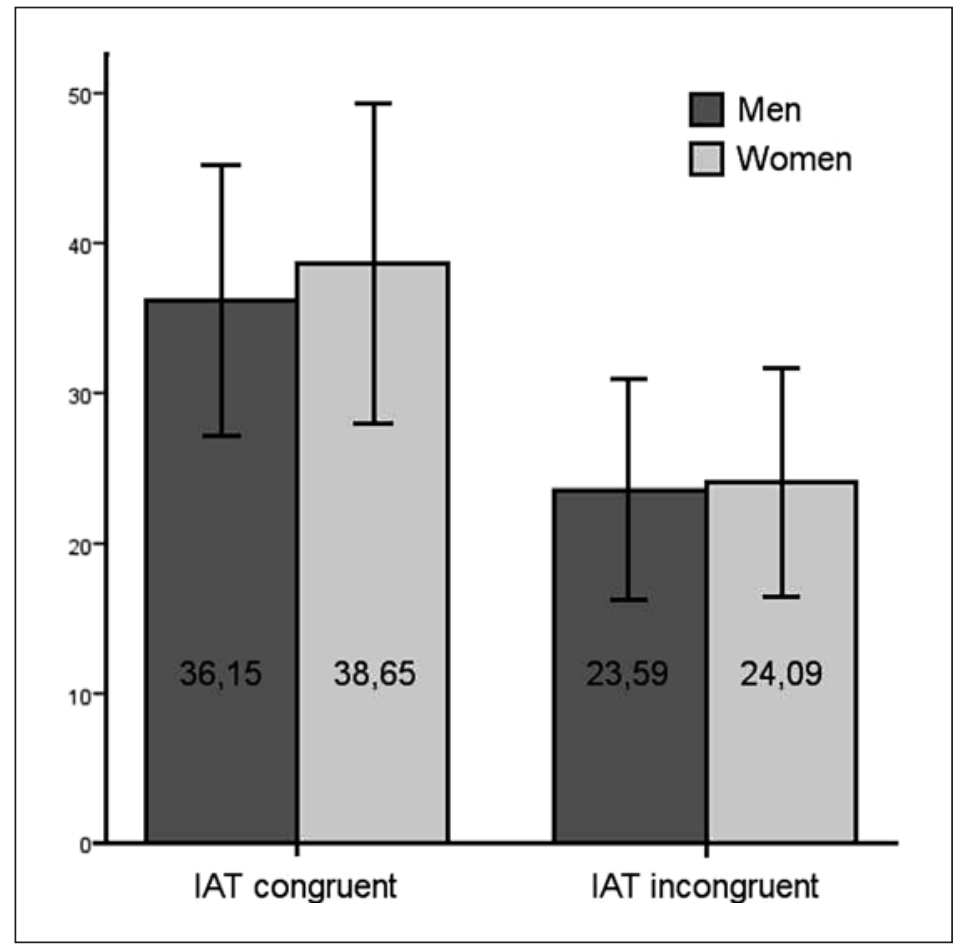

istic behavior toward opponents with obesity versus normal weight but also investigated differences in the first taken decision between groups (playing rather with an obese or a normal weight opponent). The latter was performed to encounter the assumable impact of social desirability, since the manipulation check revealed that the majority of participants anticipated the experiment correctly. We also tested the differences in altruistic behavior between the participants who did recognize the experimental manipulation and the participants who did not recognize it. In the following, results are presented according to the corresponding hypothesis.

\section{Results}

\section{Sample Characteristics}

Overall, we assessed data of 182 participants. We excluded 11 participants with a BMI equal or higher than $25 \mathrm{~kg} / \mathrm{m}^{2}$, two participants who did not speak German fluently, and 1 participant with inchoate data. A total of 168 participants remained in the study (mean age $=$ 32.51 years, $\mathrm{SD}=5.79$ ), whereas sexes were almost evenly distributed ( $52.98 \%$ female). The sample had an average BMI of $21.9 \mathrm{~kg} / \mathrm{m}^{2}(\mathrm{SD}=1.59)$ and can therefore be described as a sample of normal-weight participants. Moreover, almost three-quarters of the participants $(72.37 \%)$ stated to have a higher school degree (i.e., over 12 years in school). Participant characteristics and other descriptive variables are displayed in Table 1.

The assessed IAT data show that $5.36 \%$ of participants $(n=9)$ have more positive implicit attitudes toward people with obesity in comparison to people with normal weight and $0.6 \%$ of participants $(n=1)$ showed equal implicit attitudes to both weight groups. By contrast, the majority of participants, namely $94.05 \%(n=158)$, shows more negative implicit attitudes toward people with obesity. A paired $t$ test revealed significant differences for correct attributions made for the incongruent versus congruent task $(t(167)=19.49, p<0.001)$ (Fig. 3). Thus, 
Bernard et al.: Altruistic Behavior Depending on Opponents' Body Weight

Table 2. Stepwise linear regression model, altruistic behavior towards opponents with and without obesity ${ }^{\mathrm{a}}$

\begin{tabular}{lllllll}
\hline \multicolumn{7}{c}{ Linear regression coefficients } \\
\cline { 2 - 6 } & \multicolumn{2}{l}{ payout to obese opponent } & \multicolumn{2}{l}{ payout to nonobese opponent } \\
\hline FPS & $-0.84^{*}$ & $-0.76^{*}$ & $-0.94^{*}$ & -0.34 & -0.33 & -0.52 \\
IAT & & -0.02 & -0.03 & & -0.00 & 0.01 \\
Opponent's gender & & & 0.46 & & & 0.23 \\
$n$ & 87 & 87 & 87 & 81 & 81 & 81 \\
Adj. R & 0.05 & 0.06 & 0.04 & -0.01 & -0.02 & 0.02 \\
\hline
\end{tabular}

FPS, Fat Phobia Scale; IAT, Implicit Association Test; * $p<0.05$.

a Adjusted for participants' BMI, age, household income, gender and educational level. ${ }^{\mathrm{b}}$ Reference category: female.

participants had significant lower scores when they were asked to attribute positive adjectives (good, motivated, etc.) with obesity, which indicates a strong negative implicit association toward people with obesity. These differences also remained significant after controlling for multiple testing $(p<0.001)$. Explicit antifat attitudes, measured by FPS on a 5-point scale $(1=$ positive attitudes; 5 = negative attitudes), revealed that the examined sample tend to associate more negative attitudes toward people with obesity (mean $=3.55, \mathrm{SD}=0.47$ ).

Moreover, we aimed to examine whether participants were able to anticipate the intension of the implemented dictator game by applying a manipulation check. The majority of participants $(63.1 \%)$ correctly perceived the dictator game as an experiment to test altruistic behavior toward different body shapes. The remaining $36.9 \%$ of participants stated to have either no idea what the intention of the experiment was or anticipated decision-making behavior in general and thus not toward people with obesity in particular as underlying aim. In order to avoid biased study results due to social desirability, intraindividual differences must therefore be reflected with caution.

\section{Hypothesis 1: Altruistic Behavior toward People with Obesity}

Intraindividual differences in altruistic behavior toward normal weight versus obese opponents were examined by a $t$ test of paired data. Intraindividual analysis revealed less altruistic behavior toward obese opponents $(t(167)=-1.72, p=0.044)$. However, after we controlled for multiple testing by using family-wise Bonferroni correction, the association became insignificant (adjusted level of significance $p=0.017$ ). In addition, and in order to counteract the feasible impact of social desirability, the first taken decision of participants was compared between randomized groups (normal weight vs. obese opponent) via $t$ tests for independent samples. The difference of altruistic behavior toward obese and normal weight opponents remained insignificant between independent samples $(t(166)=-0.57, p>0.05)$.

\section{Hypothesis 2: Altruistic Behavior toward Women with Obesity}

An independent $t$ test was conducted to test for differences in altruistic behavior toward women with obesity compared to men with obesity. However, no significant differences could be found $(t(85)=-0.03, p>0.05)$.

\section{Hypothesis 3: Antifat Attitudes as Predictors for Altruistic Behavior toward Divergent Weight Groups}

We calculated two linear regression models, with altruistic behavior (amount of money shared) toward opponents with obesity or opponents with normal weight (Table 2), respec- 
Bernard et al.: Altruistic Behavior Depending on Opponents' Body Weight

tively, as outcome variables. As predictive variables, we included the explicit (FPS) and implicit (IAT) antifat attitudes. In addition, we included stepwise control variables (i.e., participants' BMI, gender, highest educational level, household income, age, and opponents' gender) in order to interpret regressions' coefficients separately. The coefficient displaying explicit antifat attitudes (FPS) was found to predict significantly $(p=0.015)$ altruistic behavior toward opponents with obesity but not toward opponents of normal weight (Table 2). Although we found significant implicit antifat attitudes, they did not significantly predict altruistic behavior toward opponents with and without obesity.

\section{Post hoc Analysis}

As post hoc analysis we conducted a correlation between altruistic behavior and implicit as well as explicit attitudes, respectively. The bivariate analyses revealed a significant association between allocated reward with an obese opponent and explicit antifat attitudes (FPS) $(r(166)=-0.17, p=0.0257)$ and implicit antifat attitudes $(r(166)=-0.15, p=0.047)$, respectively. However, after adjusting the $p$ value by using the Bonferroni correction these correlations became insignificant (adjusted level of significance $p=0.0125$ ).

In addition, we applied a two-sample $t$ test to investigate differences in altruistic behavior between the participants who did recognize the manipulation (63.1\%) and those participants who did not recognize it (36.9\%). These results can be found in the supplementary material (see www.karger.com/doi/10.1159/000501318 for all online suppl. material).

\section{Discussion}

In this study, we aimed to investigate differences in altruistic behavior between people with obesity compared to people without obesity (hypothesis 1). The hypothesized difference of altruistic behavior toward different weight groups could not be verified and must therefore be rejected. Although intraindividual analyses revealed less altruistic behavior toward obese opponents, this finding became insignificant after adjusting the level of significance by applying the Bonferroni correction. Also, intraindividual findings need to be interpreted with caution since the implemented manipulation check revealed that the majority of participants correctly anticipated the underlying idea of the dictator game. We assumed that discrimination in form of nonaltruistic behavior underlies social desirability and should thus rather be tested in a more hidden way. Therefore, group differences of the first taken decision toward obese versus normal weight opponents were investigated. An independent $t$ test revealed no significant differences of allocated reward between obese versus nonobese opponents.

Since women with obesity were notably identified as target group for stigmatization and discrimination, the study also aimed to examine differences in altruistic behavior between women with obesity compared to their male counterparts (hypothesis 2). However, no differences in altruistic behavior toward gender groups could be found.

An explanation for these results may be based on the assumption that nonaltruistic behavior (out-group discrimination) might not be as severe on individual-level compared to reported inequalities on institutional-level, such as on the healthcare, educational or on the labor market [5, 6]. In situations in which an individual might be tempted to punish or treat another individual with a stigmatized condition unfairly, social desirability might be stronger than the impulse to discriminate. Acting discriminatingly on a structural level, on the other hand, might be easier since individuals only need to follow these institutional discriminating structures that already exist [23]. 
Moreover, different experimental approaches to test differences in helping opponents to gain advantages versus helping opponents to avoid harm should be considered in future research: De Dreu and Kret [24] state that inflicting a loss is considered as more harmful and unfair than withholding a gain. Accordingly, individuals would rather help another person to avoid a negative outcome than to help another person to gain advantages. On the other hand, marginalization of out-groups can rather be found in the absence of help than in harm [25], indicating that out-group discrimination can rather be found in not favoring an out-group than in actively disadvantaging an out-group. In the here presented economic game, the dictator is in the position to help the opponent to achieve some gain, whereas the maximal "punishment" lays in withholding the total amount of monetary reward for himself. To what extent a participant would have helped in-group members to avoid harm in comparison to out-group members was not investigated and should therefore be taken into consideration in future research.

Howsoever, it must also be considered that weight status itself might not be a valid attribution that separates individuals in in- and out-groups. Altruistic behavior might not depend on weight groups but rather on explicit (and not implicit) attitudes towards certain groups (hypothesis 3).

\section{Limitations of the Study}

It must be acknowledged that the included participants do not represent a representative sample of the German population regarding education, occupational status, age, and level of income. Furthermore, future research should consider also including an overweight and obese sample to investigate not only the impact of opponents' weight status but also participants' weight status on altruistic behavior.

Also, the implemented videos presenting four different opponents were not rated in order to reveal their effect on participants in regard to sympathy or other influential factors. Therefore, it remains unclear if and which associations were triggered in participants. Moreover, we did not include scales to measure social desirability within participants that might affect altruistic behavior.

\section{Conclusion}

The aim of the study was to investigate differing altruistic behavior toward people with and without obesity and to determine moderating factors. Weight status was therefore applied as factor dividing people into in-groups (same weight status, normal weight) and outgroups (different weight status, obese). To date, no other study has investigated the impact of opponent's body weight on altruistic behavior.

Although numerous studies reported discrimination toward people with obesity in several areas of life $[5,6,17]$, the presented hypothesis, assuming less altruistic behavior of normal weight participant toward people with obesity, and in particular toward women with obesity, could not be verified. The hypotheses assuming less altruistic behavior among people with stronger explicit attitudes toward obesity could be verified. However, although we found implicit antifat attitudes among the participants, these attitudes did not predict altruistic behavior toward people of divergent weight groups. Therefore, future research should investigate (a) more intensively the diverse facets of discrimination toward people with obesity, (b) if and to what extent implicit antifat attitudes have a quantifiable impact on the stigmatization and or discrimination process, and (c) the hypotheses in a more hidden way, since manipulation check revealed that the majority of participant anticipated the underlying idea of the dictator game. 
Bernard et al.: Altruistic Behavior Depending on Opponents' Body Weight

\section{Statement of Ethics}

Subjects have given their written informed consent. The study protocol has been approved by the research institute's committee on human research.

\section{Disclosure Statement}

The authors have no conflicts of interest to declare.

\section{Funding Sources}

This study was supported by the Federal Ministry of Education and Research (BMBF), Germany, FKZ: 01E01501. The founding source had no involvement in study design, collection, analysis, and interpretation of data. Furthermore, we acknowledge support from the German Research Foundation (DFG) and University Leipzig within the program of Open Access Publishing.

\section{Author Contributions}

M.B., C.L.-S., and S.R.-H. outlined and specified the research question. M.B. and C.L.-S. conducted the statistical analysis. M.B. wrote the first draft of the manuscript. S.R.-H. and C.L.-S. revised it critically for important intellectual content. All authors contributed to and have approved the final manuscript.

\section{References}

1 Pi-Sunyer X. The medical risks of obesity. Postgrad Med. 2009 Nov;121(6):21-33.

2 Dovidio JF, Kawakami K, Johnson C, Johnson B, Howard A. On the nature of prejudice: automatic and controlled processes. J Exp Soc Psychol. 1997;33(5):510-40.

3 Link BG, Phelan JC. Conceptualizing Stigma. Annu Rev Sociol. 2001;27(1):363-85.

4 Dovidio JF, Hewstone M, Glick P, Esses VM. Prejudice, Stereotyping and Discrimination: Theoretical and Empirical Overview. In: Dovidio JF, Hewstone M, Glick P, Esses VM, editors. The SAGE handbook of prejudice, stereotyping and discrimination. 1st ed. Los Angeles: SAGE; 2010. p. 3-28.

5 Rudolph CW, Wells CL, Weller MD, Baltes BB. A meta-analysis of empirical studies of weight-based bias in the workplace. J Vocat Behav. 2009;74(1):1-10.

6 Puhl R, Brownell KD. Bias, discrimination, and obesity. Obes Res. 2001 Dec;9(12):788-805.

7 Sikorski C, Spahlholz J, Hartlev M, Riedel-Heller SG. Weight-based discrimination: an ubiquitary phenomenon? Int J Obes. 2016 Feb; 40(2):333-7.

8 Puhl RM, Latner JD, O’Brien KS, Luedicke J, Danielsdottir S, Salas XR. Potential Policies and Laws to Prohibit Weight Discrimination: Public Views from 4 Countries. Milbank Q. 2015 Dec; 93(4):691-731.

9 Tajfel H, Turner JC. An integrative theory of intergroup conflict. In: Austin WG, Worchel S, editors. The social psychology of intergroup relations. Monterey: Brooks/Cole; 1979. p. 33-37.

10 Fehr E, Fischbacher U. The nature of human altruism. Nature. 2003 Oct;425(6960):785-91.

11 Akerlof GA, Kranton R. Identity Economics. Economists Voice. 2010;7(2): https://doi.org/10.2202/15533832.1762.

12 Kahneman D, Knetsch JL, Thaler RH. Fairness and the assumptions of economics. J Bus. 1986;59(S4):S285300.

13 Gummerum M, Takezawa M, Keller M. The influence of social category and reciprocity on adults' and children's altruistic behavior. Evol Psychol. 2009;7(2):295-316.

14 Yamagishi T, Jin N, Kiyonari T. Bounded generalized reciprocity: ingroup boasting and ingroup favoritism. Adv Group Process. 1999;16:161-97. 
15 McAuliffe K, Dunham Y. Group bias in cooperative norm enforcement. Philos Trans R Soc Lond B Biol Sci. 2016 Jan;371(1686):20150073.

16 Chen Y, Li SX. Group identity and social preferences. Am Econ Rev. 2009;99(1):431-57.

17 Sikorski C, Luppa M, Brähler E, König HH, Riedel-Heller SG. Obese children, adults and senior citizens in the eyes of the general public: results of a representative study on stigma and causation of obesity. PLoS One. 2012;7(10):e46924.

18 Behnke J, Hintermaier J, Rudolph L. Die Bedeutung von Werten für Verteilungsergebnisse im Ultimatum- und Diktatorspiel. In: Behnke J, Bräuninger T, Shikano S, editors. Jahrbuch für Handlungs- und Entscheidungstheorie. Band 6: Schwerpunkt Neuere Entwicklungen des Konzepts der Rationalität und ihre Anwendungen. Wiesbaden: VS Verlag für Sozialwissenschaften; 2010. p. 165-92.

19 Greenwald AG, McGhee DE, Schwartz JL. Measuring individual differences in implicit cognition: the implicit association test. J Pers Soc Psychol. 1998 Jun;74(6):1464-80.

20 Bacon JG, Scheltema KE, Robinson BE. Fat phobia scale revisited: the short form. Int J Obes Relat Metab Disord. 2001 Feb;25(2):252-7.

21 StataCorp. Stata Statistical Software. TX: StataCorp LP; 2015.

22 Eid M, Gollwitzer M, Schmitt M. Statistik und Forschungsmethoden Lehrbuch; mit Online-Material. 4th ed. Weinheim, Basel: Beltz Verlagsgruppe; 2015.

23 Pincus FL. Discrimination comes in many forms: Individual, institutional, and structural. Am Behav Sci. 1996; 40(2):186-94.

24 De Dreu CK, Kret ME. Oxytocin Conditions Intergroup Relations Through Upregulated In-Group Empathy, Cooperation, Conformity, and Defense. Biol Psychiatry. 2016 Feb;79(3):165-73.

25 Mummendey A, Otten S. Positive-negative asymmetry in social discrimination. Eur Rev Soc Psychol. 1998; 9(1):107-43. 